THÉMATA. Revista de Filosofía

$\mathrm{N}^{\circ} 48$, julio-diciembre (2013) pp.: 227-233

ISSN: 0212-8365 e-ISSN: 2253-900X

doi: 10.12795/themata.2013.i48.20

\title{
VIVA LA GUERRA: MI CUERPO ES UN CAMPO DE BATALLA
}

\author{
LONG LIVE THE WAR: MY BODY IS A BATTLEGROUND
}

\author{
María José Galé Moyano \\ Universidad de Zaragoza (España)
}

Recibido: 20-05-2012

Aceptado: 26-06-2012

\begin{abstract}
Resumen: El proceso de devenir un cuerpo nunca resulta sencillo, es, de algún modo, una situación de permanente conflicto, entendido este de forma positiva, en el que se articulan toda una serie de ejes de emergencia que sustentan la posibilidad de comprensión de nuestra corporalidad en nuestros contextos. Si la precariedad es una condición constitutiva de la vida, esta, tal y como Judith Butler apunta, se distribuye de manera diferencial entre los seres. Tratamos de encontrar lugares, espacios de resistencia y supervivencia para albergar a una serie de corporalidades cuya precariedad es delimitada en función de la violencia estatal y de la imposición de distintas categorías de un modo férreo.

Palabras-clave: Cuerpo, sexo, género, sexualidad, precariedad, comunidad.
\end{abstract}

\begin{abstract}
The process of becoming a body is not easy. Furthermore it is a permanent conflictive situation, in a positive way. There are several emergence axis that make us, as humans, understandable in our contexts. Precariousness is a constitutive condition of life, but it is distributed through a different strenght between human beings. We are searching for places of resistance and survival for the bodies. Most of all for those bodies whose precariousness is violently inflicted by the states and the imposition of rigid cathegories.
\end{abstract}

Key-words: Body, sex, gender, sexuality, precariousness, comunity.

Cito, para configurar el título bimembre de esta breve aportación, una doble referencia a través de la cual se tratará de situar el punto de partida de una concepción de lo corporal entendido como asunto complejo, difícil de asir y en proceso de evolución constante. Para la primera parte no recogeré la celebre locución ya gramaticalizada, pronunciada en múltiples formatos en orden a reivindicar la muerte, la posibilidad de articular la violencia, la represión y de distribuir la precariedad vital entre distintos individuos, sino que -y a mi jui- 
cio con ello ya se lograría una cierta dislocación, una sutil reubicación-, arrebatándola del lugar de enunciación que suele adjudicársele como propio, tomo el título de uno de los discos del grupo musical Standstill, publicado en el año 2010. Con esta mínima maniobra, casi juego, de desplazamiento contextual y semántico de ese grito se tratará pues de atender a una noción de lo bélico que, apropiándose de la terminología, pueda trasladar el sentido, aludir a una forma de conflicto que permita el movimiento, un devenir. Y de ese modo, tratar de arrojar alguna luz sobre una terminología, una forma de representación que se ha pretendido fijar, inmovilizar, de tal modo que cuando se hable del conflicto, de lo bélico, cualquiera pueda situarse, en un brevísimo lapso de tiempo, en un contexto de interpretación.

Para la segunda parte entresaco algunas de las palabras de la obra gráfica que Barbara Kruger ideó en 1989 en un ámbito de reivindicación del aborto, y que sitúa al cuerpo en una encrucijada en que ocupa el primer lugar, el lugar del conflicto, donde los distintos discursos se entretejen en orden a la emergencia de una entidad que pueda ser viable, comprendida, leída, en el núcleo social en que habita.

Trataré de abordar la cuestión, por tanto, de la insurgencia corporal en un escenario de lucha constante que sin embargo, bajo la enseña de lo normativo y en una compleja estrategia de apropiación de los distintos cuerpos, pretende proponerse precisamente como un estado de quietud, de sosiego, de tranquilidad, como un estado "opuesto a la turbación"1. Y trataré de hacerlo centrándome fundamentalmente en uno de los ejes de sentido que permiten que las corporalidades emerjan, y al señalar que es en uno de ellos no pretendo comprenderlo como algo singular -en un sentido numérico- ni como algo unívoco, sino múltiple, puesto que abarcaría una compleja imbricación de las categorías de género, sexo y sexualidad; y, en definitiva, el intrincado haz de elementos que configuran nuestro cuerpo en relación.

En definitiva, se trataría de comprender que el conflicto, la guerra en un sentido amplio, es constitutivo a la emergencia de lo corporal en el contexto social en que se le dota de la posibilidad de vivir, de que su vida pueda ser mantenida y, a un tiempo, se trataría de reconfigurar, en alguna medida, la noción de lo bélico, abriendo la categoría, insertándonos en alguna pequeña fisura, para instalarnos de una forma activa, creativa, productiva, en la primera línea de ese devenir conflictivo de nuestra corporalidad.

Partiremos, por tanto, de un lugar, un "campo de batalla", que lejos de permanecer estático en el proceso de nuestra biografía, se modifica a lo largo del tiempo. La configuración de las distintas corporalidades "confrontadas" con el sistema de relaciones en el que emergen, se va desarrollando a lo largo de todo el proceso vital en un continuo que permite al cuerpo ser leído y compren-

[1] RAE, entrada paz.

THÉMATA. Revista de Filosofía, Nº48 julio-diciembre (2013) pp.: 227-233 doi: 10.12795/themata.2013.i48.20 
dido en relación. Este proceso no se detiene en el momento de asignación de un sexo, con anterioridad incluso al nacimiento de un ser humano, sino que se conforma de forma intensa y constante en cada uno de los encuentros que tienen lugar. Es decir, nuestra corporalidad se modifica de manera constante y su configuración no se da con independencia de los vínculos que establecemos con el resto de personas sino que constitutivamente, nuestra posibilidad de vivir, nuestra capacidad para, en palabras de Judith Butler en su texto Marcos de guerra, las vidas lloradas, "persistir y prosperar» ${ }^{2}$ depende de ellas, tanto de aquellas que conocemos como de las que nunca llegaremos a conocer y que comprenderemos siempre como anónimas.

Todas las corporalidades en este sentido, presentan como característica común esa vulnerabilidad, la "precariedad como condición compartida de la vida humana $»^{3}$. Para Butler es necesario comprender cómo, en cualquier caso, nuestra vida está siempre en manos de alguien, de otra persona. Y ello, como rasgo ontológico, es decir, inherente a lo humano. Pero, de algún modo, esta precariedad es distribuida de forma diferencial entre los distintos cuerpos a través de un aparato institucional complejo que aglutina los discursos normativos jurídico-legales, los textos anatómicos, psiquiátricos y psicológicos, las descripciones antropológicas y un compendio de aquello que se ha constituido como la cultura occidental en la contemporaneidad. Butler utiliza un término que se ha venido a traducir como "precaridad" para nombrar esa precariedad distribuida desigualmente entre los individuos hasta tal punto que hace que solo algunas vidas, de entre aquellas que se pierden, sean susceptibles de ser lloradas y por tanto sean entendidas como tales vidas dignas de duelo, de ser cuidadas, protegidas, salvaguardadas.

El punto de partida por tanto, aquí, estaría situado en la necesidad que nos impone nuestra propia vulnerabilidad constitutiva, nuestra ontología no ya como seres monádicos sino interdependientes, de mantener la vida de esas otras personas atendiendo a una necesidad de redistribución de la precariedad, de la vulnerabilidad como rasgo propio de lo humano y, por tanto, de subrayar la necesidad generalizada de determinados aspectos fundamentales para que cualquier vida pueda prosperar, es decir,

Si tomamos la precariedad de la vida como punto de partida, entonces «no hay vida sin la necesidad de cobijo y alimento, no hay vida sin una dependencia de redes más amplias de sociabilidad y trabajo, no hay vida que trascienda la dañabilidad y la mortalidad $»^{4}$.

Esta distribución de precariedad no es aleatoria, sino que se da en función de una multitud de criterios relacionados con distintas categorías que se

[2] Judith Butler, Marcos de guerra, las vidas lloradas, Barcelona, Paidós, 2010, p. 16.

[3] Ibíd., p. 30.

[4] Ibíd., p. 45.

THÉMATA. Revista de Filosofía, Nº48 julio-diciembre (2013) pp.: 227-233 doi: 10.12795/themata.2013.i48.20 
imponen a lo humano, véase cuestiones relativas al sexo, a la raza, al lugar de procedencia, al nivel sociocultural. Nos centraremos en la cuestión de la performatividad corporal atendiendo a las nociones, como señalábamos, de género, sexo, sexualidad, pero no por ello dejamos de comprender que unas y otras se interrelacionan indisolublemente dando lugar a complejas formas de jerarquización y de violencia. A pesar de todo, nuestro análisis constituye la búsqueda de un posicionamiento estratégico, provisional, siempre incompleto y, en cualquier caso, un work in progress susceptible de modificación.

La idea que guía nuestro hilo de pensamiento sería cómo algunas corporalidades, cuyas posibilidades performativas en el espacio de lo público se ven condicionadas por ciertos aspectos que las sitúan fuera de lo normativo, ven mermado el acceso a condiciones mínimas de cobijo, alimento, sociabilidad, trabajo y, en definitiva, ven debilitadas hasta el extremo sus posibilidades de vida. Y, en este caso, un mecanismo institucionalizado de distribución de "precaridad", sería aquel consistente en comprender a unos cuerpos como "normales", como "correctos" frente a otros desviados del canon por diferentes motivos, concretándose, para el caso que nos ocupa, en la acomodación o no a las normas de género que, en correspondencia con el sexo asignado, se presuponen como sustento de un determinado comportamiento sexual. Y, por otra parte, nos preocuparía dónde encontrar lugares y estrategias de resistencia a una normativización de lo sexual que permitan diluir las fronteras entre lo que es considerado lo "normal" y lo "desviado" en cuanto al sexo/género, liberándonos, o cuando menos aflojando nuestra propia identidad, del que Gayle Rubin denomina, en una metáfora de aguda intuición, «el chaleco de fuerza del género» ${ }^{5}$.

Las estrategias y los lugares a los que hacemos referencia se multiplican en todos los núcleos vitales. Desde diversas posiciones se da, en el transcurso de la cotidianeidad, un innumerable conjunto de acciones -reconocidas como tales o no- que se insertan en esa fractura de lo hegemónico; que desvelan, en alguna medida, el carácter problemático que subyace a la capacidad de cualquier corporalidad de ser leída y comprendida en su marco de referencia, la imposibilidad de performar un género, un sexo, una sexualidad, sin errores y de manera absolutamente coherente, sometiéndose a los dictados de la norma. Dichas acciones contribuyen al resquebrajamiento de esa normatividad, instalando el conflicto como algo inherente a la sujeción, al devenir sujeto. Hacen posible comprender una conflictividad constitutiva para todas las corporalidades, un proceso de guerra constante en el que se trataría de recuperar ciertos territorios, ciertos continentes a la hora de hacer visible un género, un sexo, una sexualidad, divergentes. En definitiva revelan la disponibilidad de este

[5] Gayle Rubin, "El tráfico de mujeres: notas sobre la economía política del sexo", en Marta Lamas, El género: La construcción cultural de la diferencia sexual, México, PUEG, 1996, p. 79.

THÉMATA. Revista de Filosofía, Nº48 julio-diciembre (2013) pp.: 227-233 doi: 10.12795/themata.2013.i48.20 
ámbito y de otros de la vida para ser configurados de manera creativa, activa, haciendo de ellos una "obra de arte".

$\mathrm{Y}$ en concreto, dentro del continuo de acciones que podríamos denominar de resistencia, encontraríamos algunos cuerpos que permiten, con su performatividad fronteriza, visibilizar ciertas estrategias de control de lo corporal y distintas formas de arrebatarlas de las manos de quienes pretenden adueñarse de dichas posibilidades vitales -en un "viva la muerte" que siempre alude a otras personas-, gestionando las formas y posibilidades de persistir, de mantenerse en una vida que sea susceptible de ser vivida.

Se trataría de atender a cómo esos cuerpos insurrectos a la norma de género, de sexo, de sexualidad, son capaces de articular formas de vida dentro de sus contextos. Y de cómo esos contextos se establecen como lugares de resistencia, como posibilitadores de la emergencia de identidades no hegemónicas y como garantes en definitiva de que determinadas vidas se sustenten, prosperen, persistan. Es decir, frente a la política de violencia y de muerte que pretende que solo con algunas corporalidades y en función de unos cánones se pueden dar unas condiciones de habitabilidad satisfactoria, y frente a los discursos que pretenden mantener sumergidas determinadas manifestaciones de insurgencia silenciando aportaciones, condenando al ostracismo, controlando en qué momentos surgen las imágenes, relegando la posibilidad de "decirlas" al ámbito de la medicina, la psiquiatría, la psicología y, como mucho, al arte, la cinematografía o el circo; señalar la posibilidad de proponer una vida enunciada y gestionada, siempre en la medida de lo posible, por sus propios actuantes.

Reuniríamos por una parte la aportación de Judith Butler y del pensamiento de la democracia radical contemporánea de una articulación de políticas de coalición no basada en aspectos identitarios como criterio aglutinador sino en la consecución de ciertas reivindicaciones; por otra, la atención a una identidad en cuyo devenir se debería poder participar en alguna medida; y, en tercer lugar, una perspectiva ontológica centrada en la interdependencia constitutiva y la precariedad de la vida, para proponer como vital la configuración de contextos de alianza. Unos lugares afectivos, estratégicos, en que se desplace la idea negativa del cuerpo como campo de batalla -donde solo otras personas y donde solo desde y hacia lo normativo se interviene- para acercarnos a una perspectiva positiva, creativa, por la cual comprendemos que estamos desarrollando una acción, que tratamos de paliar la violencia institucional, arrebatando aquella parte del territorio que nos es más íntima.

Estos lugares de resistencia, entendidos como una suerte de "familias" en un sentido no hegemónico del término, permiten contextos de emergencia divergentes. Supondrían, pues, un intento de dejar atrás la agrupación familiar basada en parámetros, capitalistas y heteronormativos, de control de lo humano, de división de roles y trabajos, así como de gestión y condena de las conductas sexuales que se llevan a cabo por los individuos en su seno. De este 
modo permitirían que aquellas identidades que se configuran de manera no normativa, que son excluidas del ámbito de lo normal, lo "saludable" y casi, en ocasiones, de lo humano, fuesen arropadas y no cuestionadas desde sus lugares de afecto.

Defenderíamos una postura de resistencia frente a un discurso que es capaz de, en función de criterios que podríamos denominar eugenésicos en muchas situaciones -y que suele contar con el cómplice y exhaustivo control ejercido desde el núcleo social primario en que nos desenvolvemos, léase nuestras propias familias- transformar una posibilidad de vida en algo totalmente frustrado, violento, aniquilador. Ello no supondría un deshacerse de los vínculos familiares establecidos, sino que más bien se cifraría en una revolución profunda en lo que al concepto hace referencia, pudiendo considerar los vínculos entre los seres de forma distinta. Gayle Rubin, en su artículo "El tráfico de mujeres: notas sobre la "economía política" del sexo", alude a cómo «el feminismo debe intentar una revolución en el parentesco» ${ }^{6}$. En ningún caso pretendemos señalar formas de actuación cerradas o comprender que solo a través de la canonización jurídico-legal se puede transformar en legítimo un agrupamiento. Pero esta revolución de estructuras de filiación y parentesco continúa siendo una acción urgente y en proceso que podría sostenerse como una estrategia de lucha.

La vida requiere de contextos de apoyo en que mostrarse de maneras divergentes y es necesario que estos sean reconocidos como formas legítimas de agrupamiento, sin atender al número de personas que los componen, al sexo o al género de quienes participan, al hecho de si se posee o no descendencia o a la orientación sexual. En definitiva se trataría de proponer una forma de atender a la familiaridad como algo coyuntural, no definitivo, no acabado, no conformado a partir de una serie de elementos identitarios previos o de una serie de pactos que siempre están convenidos a partir de convencionalismos muchas veces insostenibles. Propondríamos políticas de alianzas de afecto que trataran de cuestionar y subvertir lo convencional de las normativas en cuanto a lo sexual en un sentido amplio, tratando de visibilizar cómo la convención -y dentro de la misma situaríamos las ideas rígidas acerca de cómo deben ser los agrupamientos humanos- se transforma en una suerte de tortura institucional, de violencia impositiva sobre los distintos cuerpos y sobre las relaciones y vínculos que se desarrollan con quienes nos rodean. Y además, comprenderíamos que un contexto de vida, de crianza, de educación, de características distintas no solo no supondría una opción menos aceptable, sino que permitiría maximizar las oportunidades de vida. En el interior de los contextos impuestos, de los lugares previamente instituidos dentro de los cuales los individuos deben encajar a cualquier precio, no puede prosperar una vida sostenible, fundamentalmente cuando esa vida sale fuera de los cánones.

[6] Ibíd., p. 80.

THÉMATA. Revista de Filosofía, No48 julio-diciembre (2013) pp.: 227-233 doi: 10.12795/themata.2013.i48.20 
En definitiva nuestra aportación sería la de un núcleo vital en que el proceso de guerra constante con que cualquier corporalidad se desenvuelve pueda contar con personas aliadas entre aquellas que constituyen su identidad de manera intrínseca. Es necesaria la constitución de comunidades de apoyo que podamos entender de una forma tal que logren dinamitar una institución que está en la base de la organización social y que constituye un marco de emergencia para la mayor parte de los sujetos, abriendo sus posibilidades a un mayor número de formas de interacción "familiar" y a una mayor diversidad en cuanto a las personas que las configuran. 